\title{
Desempenho de Cordeiros Santa Inês Puros e Cruzas Santa Inês com Texel, Ile de France e Bergamácia ${ }^{1}$
}

\author{
Iraides Ferreira Furusho-Garcia ${ }^{2}$, Juan Ramón O. Perez ${ }^{3}$, Sarita Bonagurio ${ }^{4}$, Roberta de \\ Moura Assis ${ }^{5}$, Bruno Carneiro e Pedreira ${ }^{6}$, Xisto Rodrigues de Souza ${ }^{7}$
}

RESUMO - O trabalho foi desenvolvido com o objetivo de estudar o efeito do sexo dos animais, do grupo genético e do peso de abate no desempenho de animais confinados. Foram utilizados 103 cordeiros, machos e fêmeas, Santa Inês puros (SS) e cruzas Santa Inês com Texel (TS), Ile de France (FS) e Bergamácia (BS), confinados em gaiolas individuais. Mediram-se a dieta fornecida e as sobras diárias, para cálculo do consumo de matéria seca (MS), energia metabolizável (EM), proteína digestível (PD) e fibra em detergente neutro (FDN). Os cordeiros foram abatidos em quatro pesos: 15, 25, 35 e $45 \mathrm{~kg}$ de peso vivo. Avaliaram-se o ganho de peso diário (GPD), o número de dias no confinamento (ND), a conversão alimentar (CA) e o consumo de MS, PD, EM e FDN, nas três fases de crescimento: 15 a $25 \mathrm{~kg}$ (1), 25 a $35 \mathrm{~kg}$ (2) e 35 a $45 \mathrm{~kg}$ (3). Também foram avaliados as idades de abate (IA), o peso do corpo vazio (PCVZ) e rendimento de carcaça (RC). Aos 35 e $45 \mathrm{~kg}$, os cordeiros TS e FS apresentaram IA inferiores e as cordeiras SS, IA superiores. O ND dos cordeiros BS de 35 a $45 \mathrm{~kg}$ foi maior que dos TS. Aos 35 e $45 \mathrm{~kg}$, o PCVZ dos cordeiros TS e FS foram menores. Os melhores GPD foram dos cordeiros TS, seguidos do FS e SS. Os consumos de MS, PD, EM e FDN foram semelhantes entre os grupos genéticos, nas fases 1 e 2 de crescimento. Verificou-se que os cordeiros TS tenderam a aumentar o consumo, com o incremento de peso, enquanto os outros grupos tenderam a diminuir. A CA elevou-se com o aumento de peso, com exceção dos machos FS. Os machos não apresentaram diferenças na CA entre os grupos genéticos, entretanto, as fêmeas TS e FS apresentaram valores melhores. Aos 35 e $45 \mathrm{~kg}$, as fêmeas apresentaram maiores RC que os machos. Aos $35 \mathrm{~kg}$, os melhores RC foram dos machos TS.

Palavras-chave: consumo, cruzamento, ganho de peso, ovino

\section{Performance of Santa Inês Lambs and its Crosses with Texel, Ile de France e Bergamacia Lambs}

\begin{abstract}
The work was carried out to evaluate the effect of animal sex, genetic group and slaugher weight on fedlot lambs performance. One hundred and three male and female lambs, purebred Santa Inês (SS) and crosses between Santa Inês and Texel (TS), Ile de France (FS) and Bergamacia (BS) were fedlot in individual cages. Diet and orts were daily collected to calculate the intakes of dry matter (MS), metabolizable energy (EM), digestible protein (PD) and neutral fiber detergent (FDN). The lambs were slaughtered at four weights: $15,25,35$ and $45 \mathrm{~kg}$ of live weight. Weight gain (GPD), number of days in confinement (ND), feed:gain ratio (CA) and intakes of MS, PD, EM and FD were analyzed during three growing phases: 15 to $25 \mathrm{~kg}$ (1), 25 to 35 $\mathrm{kg}$ (2) and 35 to $45 \mathrm{~kg}$ (3), for each genetic group and each sex. The slaughter age (IA) and the empty body weight (PCVZ) were also analyzed. At high weights, TS and FS male lambs showed inferior IA, and the female lambs, superior IA. ND of BS lambs from 35 to $45 \mathrm{~kg}$ was superior than TS lambs. From 35 to $45 \mathrm{~kg}$, PCVZ of TS and FS lambs was inferior. The best GPD was observed for TS lambs, followed by FS and SS. The intakes of MS, PD, EM and FDN were similar among the genetic groups, during the phases 1 and 2. TS lambs intake tended to increase as body weight increased, whereas the other groups showed tended to decrease. CA increased as slaughter weight increased. The males did not show differences in CA among the genetic groups, but TS and FS females showed better results. At 35 and $45 \mathrm{~kg}$, the females showed superior RC than the males. At $35 \mathrm{~kg}$, the TS males showed better RC than the other groups.
\end{abstract}

Key Words: sheep, breeding, intake, weight gain

\footnotetext{
1 Parte da tese de Doutorado da primeira autora. Projeto financiado pela FAPEMIG.

2 Profa Adj. - DZO - Faculdade de Ciências Agrárias - Faculdades Federais Integradas de Diamantina - FAFEID (ifurusho@fafeod.br)

3 Prof. Titular do DZO - UFLA (jroperez@ufla.br).

${ }^{4}$ Aluna do curso de Doutorado - Unesp - Botucatu, SP (sasabona@terra.com.br).

${ }^{5}$ Aluna do curso de Mestrado em Zootecnia - UFLA

${ }^{6}$ Aluno do curso de Agronomia - ULFA (brunopedreira@uol.com.br).

${ }^{7}$ Mestre na área de Ciência dos Alimentos.
} 


\section{Introdução}

Apesar da queda do rebanho efetivo ovino (mundial e nacional), de acordo com dados da FAO (2000), a produção de carne ovina tem aumentado consideravelmente, despertando o interesse para uma produção e comercialização mais acelerada, com retorno mais rápido e qualidade do produto - um dos fatores principais para garantir o mercado. $\mathrm{Na}$ intensificação da produção, vários fatores podem ser controlados para se obter um produto de melhor qualidade, além de peso de abate ideal em menor espaço de tempo. A avaliação do ganho de peso do animal, do consumo e da conversão alimentar é fundamental, em decorrência dos custos com alimentação nesses sistemas, em que se procura animais produtivos. Esses animais, geralmente, são mais exigentes não somente quanto à alimentação, mas também em aspectos como a sanidade. Uma alternativa é o uso de animais cruzados, com uma raça especializada na produção de carne e ovelhas como as da raça Santa Inês, autóctonas.

No caso de cordeiros destinados à produção de carne, criados em confinamento, o nível nutricional deve efetivar sua potencialidade produtiva (Azzarini \& Ponzoni, 1971; Figueiró, 1979; Siqueira et al., 1984). É importante o equilíbrio entre o consumo de alimento e a produção, para evitar perda na produtividade ou excessos que ocasionam acúmulo alto de gordura, mantendo adequado custo de produção (Teixeira, 1991). Segundo Santos (1999), o conhecimento da época do desenvolvimento, onde ocorrem os maiores ganhos, é importante em função da escolha certa da hora do abate, privilegiando uma fase em que a eficiência de conversão alimentar seja ideal. De acordo com Siqueira (2000), um bom cordeiro para o confinamento deve apresentar as seguintes características: boa conversão alimentar, altas taxas de ganho e adequada deposição de gordura. Para atingir estes objetivos, deve-se planejar corretamente o sistema de produção, para a integração genéticaalimentação-manejo.

A comercialização de cordeiros, geralmente, é feita com base no peso vivo, em função da falta de adequado sistema de classificação de carcaças. Portanto, o rendimento de carcaça torna-se um parâmetro importante na comercialização (Perez, 1995; Sainz, 1996). O cordeiro, dentro da espécie ovina, é a categoria que apresenta melhores rendimentos de carcaça (Pires et al. 2000), que pode ser afetado por vários fatores: nutrição (Figueiró, 1986), genética (Siqueira, 2000; Galvão et al., 1991), peso de abate (Preston \& Willis, 1974; Pires et al. 2000) e sexo (Kemp et al, 1981). De acordo com Osório et al. (1999), a determinação de um peso de abate ideal torna-se importante para obtenção de um rendimento de carcaça economicamente viável, para machos e fêmeas de determinado grupo genético, com vistas à otimização do sistema de produção. Aumento do peso ao abate pode elevar o rendimento das carcaças (Siqueira, 2000; Oliveira et al., 1998). Porém, altos rendimentos podem estar associados a excessivo grau de gordura (Siqueira, 2000; Carson et al., 1999) ou à baixa porcentagem de componentes não-constituintes da carcaça.

Objetivou-se, com o presente trabalho, verificar o desempenho de cordeiros, machos e fêmeas de diferentes grupos genéticos (Santa Inês puro e suas cruzas com Texel, Ile de France e Bergamácia), em diferentes pesos de abate, criados em confinamento.

\section{Material e Métodos}

Foram utilizados 103 cordeiros, machos e fêmeas, provenientes de acasalamentos entre reprodutores das raças Santa Inês, Texel, Ile de France e Bergamácia com ovelhas da raça Santa Inês, denominados, respectivamente, cordeiros SS, TS, FS e BS. Todos os cordeiros nasceram no período de junho a julho de 1999 e tiveram acesso a creep feeding até a desmama (12 kg de peso vivo - PV). Posteriormente, os cordeiros passaram por um confinamento em grupo, recebendo a dieta experimental. Com exceção dos cordeiros sorteados para abate aos $15 \mathrm{~kg}$, todos os animais foram confinados individualmente aos $14 \mathrm{~kg} \mathrm{PV}$, em gaiolas $\left(1,3 \mathrm{~m}^{2}\right)$ com cochos e bebedouros separados. Os pesos dos animais foram registrados semanalmente desde a desmama até o abate, para determinação da média de ganho de peso diário (GPD). Para análise dos dados de GPD, foram consideradas as pesagens a partir de 10 dias após o início do confinamento.

A dieta experimental, fornecida à vontade, foi balanceada de acordo com as exigências do ARC (1980) para ganho de $300 \mathrm{~g} / \mathrm{dia}$, composta de $80 \%$ de concentrado e $20 \%$ de feno coastcross moído (Tabela 1 ).

$\mathrm{O}$ alimento fornecido e as sobras foram pesados diariamente, coletando-se amostras diárias, para formação das amostras compostas e posterior determinação das composições de matéria seca (MS), 
Tabela 1 - Composição percentual (\%) dos ingredientes na dieta

Table 1 - Composition of the experimental diet (\%)

\begin{tabular}{|c|c|}
\hline $\begin{array}{l}\text { Ingrediente } \\
\text { Ingredient }\end{array}$ & $\begin{array}{c}\text { \% na matéria natural } \\
\text { As fed }(\%)\end{array}$ \\
\hline Feno de coastcross & 20,00 \\
\hline Coast cross hay & \\
\hline Milho moído & 66,45 \\
\hline Ground corn & \\
\hline $\begin{array}{l}\text { Farelo de soja } \\
\text { Sovbean meal }\end{array}$ & 12,40 \\
\hline Calcário & 0,85 \\
\hline Limestone & \\
\hline Sal & 0,25 \\
\hline Salt & \\
\hline $\begin{array}{l}\text { Suplemento mineral } \\
\text { Mineral supplement }^{1}\end{array}$ & 0,01 \\
\hline $\begin{array}{l}\text { Suplemento vitamínico } \\
\text { Vitamin supplement }\end{array}$ & 0,04 \\
\hline
\end{tabular}

${ }^{1}$ Nutriente/kg de suplemento: Selênio (Selenium) $=150 \mathrm{mg}$, lodo (lodine) $=1.000 \mathrm{mg}$, Cobalto $($ Cobalt $)=600 \mathrm{mg}$, Ferro (Iron) $=$ $35.000 \mathrm{mg}$, Cobre $($ Cupper $)=20.000 \mathrm{mg}$, Manganês $($ Manganese $)=$ $49.000 \mathrm{mg}$, Zinco $($ Zinc $)=75.000 \mathrm{mg}$.

2 Nutriente/kg de suplemento: Vitamina $A=2.500 .000 \mathrm{UI}$, Vitamina D3 $500.000 \mathrm{UI}$, Vitamina E $3.000 \mathrm{mg}$, Tiamina = $750 \mathrm{mg}$, Riboflavina $=1.000 \mathrm{mcg}$, Vitamina B12 $=2.800$, Niacina $=500 \mathrm{mg}$.

proteína bruta $(\mathrm{PB})$ e fibra em detergente neutro (FDN), segundo metodologias citadas por Silva (1981).

Os animais foram abatidos em quatro pesos: 15 , 25,35 e $45 \mathrm{~kg}$. Entre aqueles abatidos aos 25,35 e $45 \mathrm{~kg}$, procedeu-se à determinação de GPD, consumo e conversão alimentar, em cada intervalo de ganho de peso ( 15 a $25 \mathrm{~kg}, 25$ a $35 \mathrm{~kg}$ e 35 a $45 \mathrm{~kg}$ ). O ganho de peso diário foi obtido a partir dos dados de pesagens semanais, considerando a média obtida de cada animal nas semanas necessárias dentro de cada fase de ganho. O consumo alimentar foi obtido a partir das anotações diárias da quantidade de alimento fornecido e das sobras, das quais foram tomadas amostras de compostas quinzenais para análises laboratoriais. A conversão alimentar foi obtida pela relação entre a quantidade de alimento consumido e o ganho de peso obtido no período.

Os animais foram pesados um dia antes do abate obtendo-se o peso vivo sem o jejum (PVSJ). Posteriormente, passaram por um jejum de dieta sólida de, aproximadamente, 16 horas. Os animais com lã foram tosquiados antes do abate. Des sa forma, a perda de peso ocorrida durante o jejum (PPJ) foi representada não somente pela diminuição do conteúdo do trato digestório, mas também pelo peso da lã retirada.
Assim, obteve-se o peso vivo em jejum (PVCJ).

No momento de abate, os animais foram atordoados e submetidos a um corte na artéria carótida e nas veias jugulares, para coleta de sangue e pele, que foram pesados. Posteriormente, foram retiradas as vísceras, pesando-se o trato gastrointestinal, bexiga e vesícula biliar, cheios e vazios, para determinação do peso corporal vazio (PCVZ). Paralelamente, foi conduzido um ensaio de digestibilidade, para determinação dos coeficientes de digestibilidade da PB e FDN, além do cálculo da energia metabolizável (EM) da dieta utilizada no confinamento dos cordeiros. Foram utilizados seis ovinos adultos alojados em gaiolas de estudos metabólicos. O período préexperimental, para adaptação, foi de 21 dias, enquanto o experimental, de cinco dias, quando foram coletadas as sobras do alimento, as fezes e a urina. Do material coletado (alimento, sobra, fezes e urina) foram retiradas amostras diárias para análises de MS, PB, FDN e energia bruta (EB). Assim, os consumos de energia metabolizável (EM) e de proteína digestível (PD) dos cordeiros do ensaio principal foram determinados.

Foram considerados dois delineamentos inteiramente casualizados (DIC) distintos. Para os caracteres PCVZ, rendimento de carcaça (RC) e idade de abate, utilizou-se um DIC, com diferentes repetições nos 32 tratamentos obtidos em um esquema fatorial $4 \times 4 \times 2$ (grupo genético, peso de abate e sexo), sendo distribuídos aleatoriamente de 3 a 5 animais em cada, portanto, um experimento desbalanceado. Para os dados de GPD, consumo de MS, PD, FDND e EM e CA, o esquema fatorial foi $4 \times 3 \times 2$ (grupo genético, fase de crescimento e sexo), em um DIC com diferentes repetições nos 24 tratamentos obtidos.

Os dados foram analisados por intermédio do SAS (SAS, 1985). As médias ajustadas foram comparadas aos pares, de acordo com teste $t$, para peso de abate de cada sexo, dentro de cada grupo genético; grupo genético de cada sexo, dentro de cada peso de abate; e sexo de cada grupo genético, dentro de cada peso de abate. Todos as fontes de variação foram estudadas separadamente, em função dos objetivos do trabalho.

Procedeu-se também à análise de regressão, pelo procedimento REG do SAS (SAS, 1985), para avaliação do efeito dos quatro diferentes pesos, para PCVZ, RC e idade de abate. Foram testados os modelos linear, quadrático e cúbico. 


\section{Resultados e Discussão}

Os consumos de matéria seca (MS), proteína digestível (PD) e fibra em detergente neutro (FDN), em $\mathrm{g} / \mathrm{kg}^{0,75} / \mathrm{dia}$ (consumo por unidade de tamanho metabólico) e energia metabolizável (EM), em $\mathrm{Mcal} / \mathrm{kg} / \mathrm{kg} 0,75 / \mathrm{dia}$, são apresentados, respectivamente, nas Tabelas 2, 3, 4 e 5. Observa-se comportamento semelhante para essas variáveis, à exceção do consumo desses nutrientes, que mostrou variações semelhantes, em função do fator perdominante (sexo, grupo genético ou fase de crescimento), independentemente do nutriente, explicado pela limitação proporcionada pelo consumo da matéria seca. As únicas diferenças observadas entre machos e fêmeas ocorreram para o grupo SS, para o consumo de MS, PD e EM, nas segunda e terceira fases, em que os machos consumiram quantidades maiores $(\mathrm{P}<0,05)$ que as fêmeas, provavelmente em decorrência do maior metabolismo dos machos nessas fases, exigindo maior consumo de alimento. Para o consumo de FDN, não houve diferenças entre os sexos. Na primeira fase, não houve diferenças entre os grupos genéticos para os cordeiros machos, para o consumo de todos os nutrientes. As fêmeas TS apresentaram, nesta primeira fase, menor $(\mathrm{P}<0,05)$ consumo de MS e de EM que as fêmeas FS e BS, comprovando que, em fase inicial de crescimento, necessitam de menor quantidade, principalmente, de energia. Na segunda fase, os machos BS consumiram menores quantidades $(\mathrm{P}<0,05)$ que os cordeiros $\mathrm{SS}$, TS e FS, enquanto as fêmeas SS e BS consumiram menos $(\mathrm{P}<0,05)$ que as cordeiras FS, com exceção do consumo de FDN, que foi igual para todas as fêmeas nesta fase. Na $3^{\text {a }}$ fase, observou-se que as fêmeas SS consumiram menores $(\mathrm{P}<0,05)$ quantidades de $\mathrm{MS}$, PD e EM, comprovando que cordeiras puras Santa Inês possuem menor capacidade de consumo. Ainda nesta última fase de crescimento, as cordeiras BS consumiram menos $(\mathrm{P}<0,05)$ que as TS e quantidades semelhantes às cordeiras $\mathrm{FS}$, em razão de maior exigência com o uso das raças especializadas, o que também explica o fato de os machos TS consumirem maiores $(\mathrm{P}<0,05)$ quantidades que os SS e BS. Nesta fase, as fêmeas SS consumiram menores quantidades de FDN que as fêmeas TS e FS, em decorrência do menor consumo da matéria seca; os machos não apresentaram diferenças entre os grupos genéticos.

Com o avanço da fase de crescimento, machos e fêmeas SS e BS e fêmeas FS diminuíram o consumo de MS, PD e EM, enquanto machos TS e as fêmeas TS e FS mantiveram consumos semelhantes durante as três fases, indicando possível diferença na exigência de nutrientes, quando se utilizam animais de raças especilizadas, que normalmente são mais exigentes,

Tabela 2 - Médias de consumo de matéria seca ( $/ \mathrm{kg}$ 0,75/dia) para cordeiros Santa Inês puros (SS) e cruzas com Texel (TS), lle de France (FS) e Bergamácia (BS) e respectivos erros-padrão (ep)

Table 2 - Means of dry matter intake ( $/ \mathrm{kg} .75 /$ day) of purebred Santa Inês (SS) lambs and its crosses with Texel (TS), Ile de France (FS) and Bergamacia (BS) and the respective standard errors (ep)

\begin{tabular}{|c|c|c|c|c|c|c|c|}
\hline \multirow[t]{2}{*}{$\begin{array}{l}\text { Grupo genético } \\
\text { Genetic group }\end{array}$} & \multirow[t]{2}{*}{$\begin{array}{l}\text { Sexo } \\
\text { Sex }\end{array}$} & \multicolumn{2}{|c|}{$\begin{array}{l}1 \underline{\mathrm{a}} \text { fase } \\
1^{\text {st }} \text { phase }\end{array}$} & \multicolumn{2}{|c|}{$\begin{array}{c}2 \underline{\mathrm{a}} \text { fase } \\
2^{\text {nd }} \text { phase }\end{array}$} & \multicolumn{2}{|c|}{$\begin{array}{c}3 \mathrm{a} \text { fase } \\
3^{\text {rd }} \text { phase }\end{array}$} \\
\hline & & $15-25 \mathrm{~kg}$ & ep & $25-35 \mathrm{~kg}$ & ep & $35-45 \mathrm{~kg}$ & ep \\
\hline \multirow[t]{2}{*}{ SS } & $\mathrm{M}$ & $74,82^{\mathrm{AaA}}$ & 3,12 & $76,24^{\mathrm{BaA}}$ & 3,60 & $64,94^{\mathrm{BaB}}$ & 3,60 \\
\hline & $\mathrm{F}$ & $76,85^{\text {Aaab }}$ & 3,12 & $63,24^{\mathrm{ABbb}}$ & 3,12 & $54,29^{\mathrm{Bbc}}$ & 3,60 \\
\hline \multirow[t]{2}{*}{ TS } & M & $71,63^{\mathrm{AaA}}$ & 3,60 & $75,59^{\mathrm{AaA}}$ & 3,60 & $77,62^{\mathrm{AaA}}$ & 3,12 \\
\hline & $\mathrm{F}$ & $69,49^{\text {Aab }}$ & 3,12 & $69,34^{\text {Aaab }}$ & 3,12 & $73,38^{\text {Ааa }}$ & 3,60 \\
\hline \multirow[t]{2}{*}{ FS } & M & $77,61^{\mathrm{AaA}}$ & 3,60 & $79,51^{\mathrm{AaA}}$ & 3,60 & $71,00^{\mathrm{AaAB}}$ & 4,41 \\
\hline & $\mathrm{F}$ & $86,35^{\text {Ааa }}$ & 4,41 & $77,09^{\mathrm{AB} a \mathrm{a}}$ & 4,41 & $71,87^{\text {Baab }}$ & 4,41 \\
\hline \multirow[t]{2}{*}{ BS } & $\mathrm{M}$ & $74,13^{\mathrm{AaA}}$ & 3,12 & $62,91^{\mathrm{BaB}}$ & 4,41 & $64,01^{\mathrm{BaB}}$ & 3,60 \\
\hline & $\mathrm{F}$ & $78,07^{\text {Ааa }}$ & 3,12 & $61,71^{\mathrm{Bab}}$ & 2,79 & $63,35^{\mathrm{Bab}}$ & 2,79 \\
\hline
\end{tabular}

Médias seguidas de letras diferentes diferem entre si pelo teste $t(P<0,05)$. Nas linhas, letras maiúsculas para diferenciar as fases de crescimento; nas colunas: minúsculas para diferenciar o sexo em cada grupo genético, minúscula em negrito para diferenciar o grupo genético nas fêmeas e maiúscula em negrito para diferenciar o grupo genético nos machos. Means followed by different letters differ $(P<.05)$ by $t$ test. In the lines, capital letters are used to differentiate the growth phases; in the columns: small letters are used to differentiate sex in each genetic group, small letters in boldface are used to differentiate the genetic group in the females and capital letters in boldface differentiate the genetic group in the males.

$\mathrm{M}=$ Macho $($ Male $)$ e $\mathrm{F}=$ Fêmea $($ Female) .

\section{R. Bras. Zootec., v.33, n.6, p.1591-1603, 2004}


Tabela 3 - Médias de consumo de proteína digestível ( $\left./ \mathrm{kg}^{0,75} / \mathrm{dia}\right)$ para cordeiros Santa Inês puros (SS) e cruzas com Texel (TS), lle de France (FS) e Bergamácia (BS) e respectivos erros-padrão (ep)

Table 3 - Means of digestible protein intake ( $/ \mathrm{kg} .75 /$ day) of purebred Santa Inês (SS) lambs and its crosses with Texel (TS), Ile de France (FS) and Bergamacia (BS) and the respective standard errors (ep)

\begin{tabular}{|c|c|c|c|c|c|c|c|}
\hline \multirow[t]{2}{*}{$\begin{array}{l}\text { Grupo genético } \\
\text { Genetic group }\end{array}$} & \multirow[t]{2}{*}{$\begin{array}{l}\mathrm{Sexo}^{2} \\
\mathrm{Sex}^{2}\end{array}$} & \multicolumn{2}{|c|}{$\begin{array}{c}1 \stackrel{\mathrm{a}}{ } \text { fase } \\
1^{\text {st }} \text { phase }\end{array}$} & \multicolumn{2}{|c|}{$\begin{array}{c}2 \underline{\mathrm{a}} \text { fase } \\
2^{\text {nd }} \text { phase }\end{array}$} & \multicolumn{2}{|c|}{$\begin{array}{c}3 \underline{\mathrm{a}} \text { fase } \\
3^{\text {rd }} \text { phase }\end{array}$} \\
\hline & & $15-25 \mathrm{~kg}$ & ep & $25-35 \mathrm{~kg}$ & ep & $35-45 \mathrm{~kg}$ & ep \\
\hline \multirow[t]{2}{*}{ SS } & $M$ & $7,57 \mathrm{AaA}$ & 0,32 & $7,77^{\mathrm{AaA}}$ & 0,37 & $6,57^{\mathrm{BaB}}$ & 0,37 \\
\hline & $\mathrm{F}$ & $7,88^{\text {Aaab }}$ & 0,32 & $6,39^{\mathrm{Bb} b}$ & 0,32 & $5,49^{\mathrm{Bbc}}$ & 0,37 \\
\hline \multirow[t]{2}{*}{ TS } & M & $7,26^{\mathrm{AaA}}$ & 0,37 & $7,70^{\mathrm{AaA}}$ & 0,37 & $7,89^{\mathrm{AaA}}$ & 0,32 \\
\hline & $\mathrm{F}$ & $7,12^{\text {Aab }}$ & 0,32 & $7,04^{\text {Ааab }}$ & 0,32 & 7,38 Ааа & 0,37 \\
\hline \multirow[t]{2}{*}{ FS } & $\mathrm{M}$ & $7,93^{\mathrm{AaA}}$ & 0,37 & $8,08^{\mathrm{AaA}}$ & 0,37 & $7,26^{\mathrm{AaAB}}$ & 0,46 \\
\hline & $\mathrm{F}$ & $8,85^{\text {Ааa }}$ & 0,46 & $7,79^{\mathrm{ABaa}}$ & 0,46 & $7,23^{\text {Baab }}$ & 0,46 \\
\hline \multirow[t]{2}{*}{ BS } & M & $7,54^{\mathrm{AaA}}$ & 0,32 & $6,36^{\mathrm{BaB}}$ & 0,46 & $6,41^{\mathrm{Ba} \mathbf{B}}$ & 0,37 \\
\hline & $\mathrm{F}$ & $7,92^{\text {Aaab }}$ & 0,32 & $6,22^{\mathrm{Bab}}$ & 0,29 & $6,40^{\mathrm{Bab}}$ & 0,29 \\
\hline
\end{tabular}

Médias, seguidas de letras diferentes, diferem entre si pelo teste $t(P<0,05)$. Nas linhas, letras maiúsculas para diferenciar as fases de crescimento; nas colunas: minúsculas para diferenciar o sexo em cada grupo genético, minúscula em negrito para diferenciar o grupo genético nas fêmeas e maiúscula em negrito para diferenciar o grupo genético nos machos. Means followed by different letters, differ $(P<.05)$ by test $t$. In the lines, capital letters are used to differentiate the growth phases; in the columns: small letters are used to differentiate sex in each genetic group, small letters in boldface are used to differentiate the genetic group in the females and capital letters in boldface differentiate the genetic group in the males.

$\mathrm{M}=$ Macho $($ Male) e F = Fêmea (Female) .

Tabela 4 - Médias de consumo de fibra em detergente neutro ( $\left./ \mathrm{kg}^{0,75} / \mathrm{dia}\right)$ para cordeiros Santa Inês puros (SS), e cruzas com Texel (TS), lle de France (FS) e Bergamácia (BS) e respectivos erros-padrão (ep)

Table 4 - Means of neutral detergent fiber intake ( $/ \mathrm{kg} .75 /$ day) of purebred Santa Inês (SS) lambs and its crosses with Texel (TS), Ile de France (FS) and Bergamacia (BS) and the respective standard errors (ep)

\begin{tabular}{|c|c|c|c|c|c|c|c|}
\hline \multirow[t]{2}{*}{$\begin{array}{l}\text { Grupo genético } \\
\text { Genetic group }\end{array}$} & \multirow[t]{2}{*}{$\begin{array}{l}\text { Sexo } \\
\text { Sex }\end{array}$} & \multicolumn{2}{|c|}{$\begin{array}{l}1 \stackrel{\mathrm{a}}{\text { fase }} \\
1^{\text {st }} \text { phase }\end{array}$} & \multicolumn{2}{|c|}{$\begin{array}{c}2 \underline{a} \text { fase } \\
2^{\text {nd }} \text { phase }\end{array}$} & \multicolumn{2}{|c|}{$\begin{array}{c}3 \underline{\mathrm{a}} \text { fase } \\
3^{\text {rd }} \text { phase }\end{array}$} \\
\hline & & $15-25 \mathrm{~kg}$ & ep & $25-35 \mathrm{~kg}$ & ep & $35-45 \mathrm{~kg}$ & ep \\
\hline \multirow[t]{2}{*}{ SS } & $\mathrm{M}$ & $15,64^{\mathrm{AaA}}$ & 1,08 & $16,39^{\mathrm{AaA}}$ & 1,25 & $15,23^{\mathrm{AaA}}$ & 1,25 \\
\hline & $\mathrm{F}$ & $15,94^{\text {Аaab }}$ & 1,08 & $13,43^{\mathrm{ABaa}}$ & 1,08 & $12,07^{\mathrm{Bab}}$ & 1,25 \\
\hline \multirow[t]{2}{*}{$\mathrm{TS}$} & M & $16,03^{\mathrm{AaA}}$ & 1,25 & $16,79^{\mathrm{AaA}}$ & 1,25 & $17,39^{\mathrm{AaA}}$ & 1,08 \\
\hline & $\mathrm{F}$ & $14,48^{\text {Aab }}$ & 1,08 & $15,08^{\text {Ааа }}$ & 1,08 & $15,67^{\text {Ааa }}$ & 1,25 \\
\hline \multirow[t]{2}{*}{ FS } & M & $15,64^{\mathrm{AaA}}$ & 1,25 & $17,90^{\mathrm{AaA}}$ & 1,25 & $15,75^{\mathrm{AaA}}$ & 1,53 \\
\hline & $\mathrm{F}$ & $19,07^{\text {Ааa }}$ & 1,53 & $15,86^{\text {Ааa }}$ & 1,53 & $17,17^{\mathrm{Aaa}}$ & 1,53 \\
\hline \multirow[t]{2}{*}{ BS } & M & $16,74^{\mathrm{AaA}}$ & 1,08 & $12,42^{\mathrm{Ba} B}$ & 1,53 & $14,31^{\mathrm{ABaA}}$ & 1,25 \\
\hline & $\mathrm{F}$ & $16,68^{\text {Aaab }}$ & 1,08 & $12,88^{\text {Ваa }}$ & 0,97 & $13,07^{\text {Baab }}$ & 0,97 \\
\hline
\end{tabular}

Médias seguidas de letras diferentes diferem entre si pelo teste $t(P<0,05)$. Nas linhas, letras maiúsculas para diferenciar as fases de crescimento; nas colunas: minúsculas para diferenciar o sexo em cada grupo genético, minúscula em negrito para diferenciar o grupo genético nas fêmeas e maiúscula em negrito para diferenciar o grupo genético nos machos. Means followed by different letters differ $(P<.05)$ by $t$ test. In the lines, capital letters are used to differentiate the growth phases; in the columns: small letters are used to differentiate sex in each genetic group, small letters in boldface are used to differentiate the genetic group in the females and capital letters in boldface differentiate the genetic group in the males.

$\mathrm{M}=$ Macho $($ Male $)$ e F = Fêmea (Female).

sobretudo na fase de crescimento. $\mathrm{O}$ resultado obtido neste trabalho contraria os relatados por Wolf et al. (1980), que atribuem o baixo teor de carne magra dos cordeiros cruzas Texel ao baixo apetite, e também discorda do observado por Kempster et al. (1987), que atribuíram o baixo crescimento dos cruzas Texel ao reduzido consumo alimentar. Entretanto, os trabalhos relatados fazem comparações com animais de raças especializadas, enquanto, nesta pesquisa, está envolvida uma raça autócna, no caso a Santa Inês.

O consumo médio de MS para todos os grupos, entre 25 e $35 \mathrm{~kg}$, foi de $0,913 \mathrm{~kg} / \mathrm{dia} /$ animal, inferior ao valor citado por Latif \& Owen (1980) e Carvalho et al. (1999), respectivamente, 1,071 e 1,460 kg/dia/animal 
Tabela 5 - Médias de consumo de energia metabolizável ( $\mathrm{kcal} / \mathrm{kg} 0,75 / \mathrm{kg} / \mathrm{dia}$ ) para cordeiros Santa Inês puros (SS) e cruzas com Texel (TS), lle de France (FS) e Bergamácia (BS) e respectivos erros-padrão (ep)

Table 5 - Means of metabolizable energy intake ( $\mathrm{kcal} / \mathrm{kg} \cdot 75 / \mathrm{kg} /$ day) of purebred Santa Inês (SS) lambs and its crosses with Texel (TS), Ile de France (FS) and Bergamácia (BS) and the respective standard errors (ep)

\begin{tabular}{|c|c|c|c|c|c|c|c|}
\hline \multirow[t]{2}{*}{$\begin{array}{c}\text { Grupo genético } \\
\text { Genetic group }\end{array}$} & \multirow[t]{2}{*}{$\begin{array}{l}\text { Sexo } \\
\text { Sex }\end{array}$} & \multicolumn{2}{|c|}{$\begin{array}{l}1 \underline{\mathrm{a}} \text { fase } \\
1^{\text {st }} \text { phase }\end{array}$} & \multicolumn{2}{|c|}{$\begin{array}{c}2 \frac{\mathrm{a}}{\text { fase }} \\
2^{\text {nd }} \text { phase }\end{array}$} & \multicolumn{2}{|c|}{$\begin{array}{l}3 \underline{\mathrm{a}} \text { fase } \\
3^{\text {rd }} \text { phase }\end{array}$} \\
\hline & & $15-25 \mathrm{~kg}$ & ep & $25-35 \mathrm{~kg}$ & ep & $35-45 \mathrm{~kg}$ & ep \\
\hline \multirow[t]{2}{*}{ SS } & $\mathrm{M}$ & $197,75^{\mathrm{AaA}}$ & 8,23 & $201,50^{\mathrm{AaA}}$ & 9,51 & $171,62^{\mathrm{Ba} B}$ & 9,51 \\
\hline & $\mathrm{F}$ & $203,11^{\text {Aaab }}$ & 8,23 & $167,13^{\mathrm{Bbb}}$ & 8,23 & $143,49^{\mathrm{Cbc}}$ & 9,51 \\
\hline \multirow[t]{2}{*}{ TS } & M & $189,32^{\mathrm{AaA}}$ & 9,51 & $199,80^{\mathrm{AaA}}$ & 9,51 & $205,15^{\mathrm{AaA}}$ & 8,23 \\
\hline & $\mathrm{F}$ & $183,66^{\text {Aab }}$ & 8,23 & $183,28^{\text {Aaab }}$ & 8,23 & $193,94^{\text {Ааа }}$ & 9,51 \\
\hline \multirow{2}{*}{ FS } & M & $205,13^{\mathrm{AaA}}$ & 9,51 & $210,14^{\mathrm{AaA}}$ & 9,51 & $187,65^{\mathrm{AaAB}}$ & 11,64 \\
\hline & $\mathrm{F}$ & $228,23^{\text {Ааа }}$ & 11,64 & $203,76^{\text {АВаa }}$ & 11,64 & $189,96^{\text {Ваab }}$ & 11.64 \\
\hline \multirow[t]{2}{*}{ BS } & $\mathrm{M}$ & $195,93^{\mathrm{AaA}}$ & 8,23 & $166,27^{\mathrm{BaB}}$ & 11,64 & $169,18^{\mathrm{Ba} \mathbf{B}}$ & 9,51 \\
\hline & $\mathrm{F}$ & $206,34^{\text {Ааа }}$ & 8,23 & $163,10^{\mathrm{Bab}}$ & 7,36 & $167,43^{\mathrm{Bab}}$ & 7,36 \\
\hline
\end{tabular}

Médias seguidas de letras diferentes diferem entre si pelo teste $t(P<0,05)$. Nas linhas, letras maiúsculas para diferenciar as fases de crescimento; nas colunas: minúsculas para diferenciar o sexo em cada grupo genético, minúscula em negrito para diferenciar o grupo genético nas fêmeas e maiúscula em negrito para diferenciar o grupo genético nos machos. Means followed by different letters differ $(P<.05)$ by $t$ test. In the lines, capital letters are used to differentiate the growth phases; in the columns: small letters are used to differentiate sex in each genetic group, small letters in boldface are used to differentiate the genetic group in the females and capital letters in boldface differentiate the genetic group in the males.

$\mathrm{M}=$ Macho (Male) e F = Fêmea (Female).

para cordeiros Texel x Finn Dorset. O valor de consumo de MS foi superior aos citados por Pires et al. (2000) e Kirkpatrick \& Steen (1999), que encontraram, respectivamente, consumo médio de 712 e $521 \mathrm{~g} /$ dia para cordeiros cruzas Texel x Ideal e cordeiros terminados em confinamento. Furusho (1995) cita consumo de MS, para cordeiros cruzas Texel x Santa Inês, superior (1.145 g/dia) ao encontrado no presente trabalho e que não proporcionou o mesmo ganho de peso (208 g/dia vs $258 \mathrm{~g} /$ dia).

Os resultados para conversão alimentar média (CA) são mostrados na Tabela 6. Na primeira fase de crescimento, não houve diferenças entre os grupos genéticos, para machos e fêmeas. Os cordeiros machos SS e BS, na 2a e $3 \underline{a}$ fases, apresentaram melhor $(\mathrm{P}<0,05) \mathrm{CA}$ que as fêmeas dos mesmos grupos, em razão da maior capacidade dos machos em converter alimentos em tecido corporal. Na 2 a fase, as cordeiras BS apresentaram pior $(\mathrm{P}<0,05) \mathrm{CA}$ que as cordeiras FS e TS, ao passo que as SS, CA semelhante à das TS e FS. Na terceira fase, as fêmeas do grupo genético FS tiveram melhor $(\mathrm{P}<0,05)$ conversão alimentar que as cordeiras SS e BS. A CA das cordeiras TS foi semelhante à das FS e SS e melhor $(\mathrm{P}<0,05)$ que a das BS. Os resultados mostram que fêmeas da raça Santa Inês podem apresentar desempenho, em determinadas fases do desenvolvimento, semelhante ao de animais cruzas com raças especializadas, comprovando o potencial dessa raça nacional para a produção de carne. Os cordeiros machos do grupo FS não apresentaram variações significativas na CA, com o aumento da fase de crescimento, ao contrário dos outros grupos, em que foi observado aumento desta variável. Diminuição da eficiência na conversão alimentar, com o avanço do tempo, é indicativo de que o produtor deve procurar programar os abates, em uma fase com conversão não tão alta, para não onerar o custo de produção. Os dados de CA foram diferentes dos encontrados por Santos (1999), que obteve o melhor valor para CA entre 25 e $35 \mathrm{~kg}$ de peso vivo, enquanto, no presente trabalho, os melhores valores foram encontrados entre 15 e 25 $\mathrm{kg}$. Até $35 \mathrm{~kg}$, a CA média obtida pelos cordeiros machos cruzas TS foi de 3,22. Esse valor foi melhor que os encontrados por Latif \& Owen (1980), de 3,42, para cordeiros Texel x Finn Dorset criados em confinamento; Preziuso et al. (1999), de 4,63, para cordeiros confinados entre 45 e 105 dias de idade; Pires et al. (2000), de 4,32, para cordeiros cruzas Texel x Ideal; e Carvalho et al. (1999), valor médio de 4,60. Furusho (1995) constatou, para cordeiros cruzas Santa Inês x Texel, valor superior ao do 
Tabela 6 - Médias de conversão alimentar (g) para cordeiros Santa Inês puros (SS) e cruzas com Texel (ST), lle de France (SF) e Bergamácia (SB) e respectivos erros-padrão (ep)

Table 6 - Means of feed:gain ratio of purebred Santa Inês (SS) lambs and its crosses with Texel (TS), Ile de France (FS) and Bergamacia (BS) and the respective standard errors (ep)

\begin{tabular}{|c|c|c|c|c|c|c|c|}
\hline \multirow[t]{2}{*}{$\begin{array}{c}\text { Grupo genético } \\
\text { Genetic group }\end{array}$} & \multirow[t]{2}{*}{$\begin{array}{l}\text { Sexo } \\
\text { Sex }\end{array}$} & \multicolumn{2}{|c|}{$\begin{array}{l}1 \underline{\mathrm{a}} \text { fase } \\
1^{\text {st }} \text { phase }\end{array}$} & \multicolumn{2}{|c|}{$\begin{array}{c}2 \frac{\mathrm{a}}{\text { fase }} \\
2^{\text {nd }} \text { phase }\end{array}$} & \multicolumn{2}{|c|}{$\begin{array}{l}3 \text { a fase } \\
3^{\text {rd }} \text { phase }\end{array}$} \\
\hline & & $15-25 \mathrm{~kg}$ & ep & $25-35 \mathrm{~kg}$ & ep & $35-45 \mathrm{~kg}$ & ep \\
\hline \multirow[t]{2}{*}{ SS } & $\mathrm{M}$ & $3,51^{\mathrm{BaA}}$ & 0,50 & $4,23^{\mathrm{BbA}}$ & 0,57 & $5,93^{\mathrm{AbA}}$ & 0,57 \\
\hline & $\mathrm{F}$ & $4,33^{\text {Саa }}$ & 0,50 & $5,83^{\text {Baab }}$ & 0,50 & $7,67^{\text {Aaab }}$ & 0,57 \\
\hline \multirow[t]{2}{*}{ TS } & M & $2,94^{\mathrm{BaA}}$ & 0,57 & $3,50^{\mathrm{ABaA}}$ & 0,57 & $4,79^{\mathrm{AaA}}$ & 0,50 \\
\hline & $\mathrm{F}$ & 3,29 Саа & 0,50 & $4,71^{\mathrm{Bab}}$ & 0,50 & $6,17^{\text {Aabc }}$ & 0,57 \\
\hline \multirow[t]{2}{*}{ FS } & M & $3,07 \mathrm{AaA}$ & 0,57 & $3,51^{\mathrm{AaA}}$ & 0,57 & $4,72^{\mathrm{AaA}}$ & 0,70 \\
\hline & $\mathrm{F}$ & $3,63^{\text {Ваa }}$ & 0,70 & $5,08^{\mathrm{ABab}}$ & 0,70 & $5,77^{\text {Аас }}$ & 0,70 \\
\hline \multirow[t]{2}{*}{ BS } & $\mathrm{M}$ & $3,29^{\mathrm{BaA}}$ & 0,50 & $5,08^{\mathrm{AbA}}$ & 0,70 & $6,06^{\mathrm{AbA}}$ & 0,57 \\
\hline & $\mathrm{F}$ & $3,88^{\mathrm{Ca}}$ & 0,50 & $6,78^{\mathrm{Baa}}$ & 0,44 & $8,26^{\text {Ааa }}$ & 0,44 \\
\hline
\end{tabular}

Médias seguidas de letras diferentes diferem entre si pelo teste $t(P<0,05)$. Nas linhas, letras maiúsculas para diferenciar as fases de crescimento; nas colunas: minúsculas para diferenciar o sexo em cada grupo genético, minúscula em negrito para diferenciar o grupo genético nas fêmeas e maiúscula em negrito para diferenciar o grupo genético nos machos. Means followed by different letters differ $(P<.05)$ by $t$ test. In the lines, capital letters are used to differentiate the growth phases; in the columns: small letters are used to differentiate sex in each genetic group, small letters in boldface are used to differentiate the genetic group in the females and capital letters in boldface differentiate the genetic group in the males. $\mathrm{M}=$ Macho $($ Male $)$ e $\mathrm{F}=$ Fêmea $($ Female $)$.

presente trabalho $(6,50)$. De acordo com Latif \& Owen (1980), é esperada taxa de conversão alimentar inferior para cordeiros filhos de Texel, graças a seu longo período de alimentação e alto requerimento para mantença. Entretanto, os mesmos autores citaram que o baixo conteúdo de gordura de cordeiros cruzas Texel acarreta maior taxa de conversão alimentar, o que não aconteceu neste trabalho.

Os resultados de ganho de peso diário (GPD) são mostrados na Tabela 7. Para os animais dos grupos SS e TS, houve diferenças $(\mathrm{P}<0,05)$ entre machos $\mathrm{e}$ fêmeas na segunda e terceira fases de crescimento, sendo que os machos apresentaram maior ganho. Os machos FS também obtiveram ganhos maiores $(\mathrm{P}<0,05)$ que as fêmeas FS, mas somente na $2^{\mathrm{a}}$ fase. Segundo Latif \& Owen (1980), Crouse et al. (1992) e Pires et al. (2000), os machos se desenvolvem mais rapidamente que as fêmeas. Entretanto, no presente trabalho, o grupo BS não apresentou diferenças entre sexos nas fases avaliadas. Apesar da ausência de diferenças no grupo FS, abatido aos $45 \mathrm{~kg}$, os machos apresentaram ganho médio de $244 \mathrm{~g} /$ dia e as fêmeas, de $199 \mathrm{~g} / \mathrm{dia}$, valores que, para o produtor, devem ser considerados, pois, por exemplo, no decorrer de 50 dias de confinamento, os machos ganhariam $12,2 \mathrm{~kg}$ de peso, enquanto as fêmeas, apenas $9,95 \mathrm{~kg}$, uma diferença de $2,25 \mathrm{~kg}$. Considerando-se que em torno de $50 \%$ é carcaça, obter-se-ia $1,125 \mathrm{~kg}$, que, em um grupo de 100 animais confinados para abate, seria
$112,5 \mathrm{~kg}$ de carcaça a menos, se confinasse fêmeas em vez de machos. Apesar de existirem outros fatores, a explicação acima serve apenas para destacar que, às vezes, mesmo não havendo diferenças entre as comparações, é possível escolher o tipo de animal para determinado fim. Entre 15 e $25 \mathrm{~kg}$ de peso vivo, não houve diferenças entre os grupos genéticos, para os cordeiros machos e fêmeas. Na segunda fase (25 e $35 \mathrm{~kg}$ ), os cordeiros machos SS, TS e FS apresentaram ganhos melhores $(\mathrm{P}<0,05)$ que os $\mathrm{BS}$; o mesmo ocorreu para as cordeiras TS e FS em relação às BS. Na terceira fase (35 e $45 \mathrm{~kg}$ ), as cordeiras cruzas TS e FS foram melhores $(\mathrm{P}<0,05)$ que as fêmeas SS e BS. Os machos TS obtiveram melhores $(\mathrm{P}<0,05)$ ganhos que os cordeiros $\mathrm{SS}$ e BS e os FS, ganhos superiores $(\mathrm{P}<0,05)$ aos cordeiros BS. Os resultados médios, durante as três fases de crescimento, obtidos para os cordeiros cruzas com Texel (258 e 196 g/dia, respectivamente, para machos e fêmeas), são um pouco inferiores aos encontrados por Latif \& Owen (1980), para animais cruzas Texel x Finn Dorset, abatidos com peso médio de $33 \mathrm{~kg}$, que registraram ganhos de 285 e 250 g/dia, respectivamente, para machos e fêmeas. Os ganhos obtidos, nesta pesquisa, para machos TS abatidos com $45 \mathrm{~kg}$ de peso vivo e 185 dias de idade, foram superiores ao encontrado por Furusho (1995), média de $208 \mathrm{~g}$ /dia para cordeiros TS abatidos com 180 dias de idade. Em função dos resultados obtidos na segunda 
Tabela 7 - Valores médios para ganho de peso diário ( $\mathrm{kg} / \mathrm{dia}$ ) de cordeiros Santa Inês puros (SS) e cruzas com Texel (TS), lle de France (FS) e Bergamácia (BS) e respectivos erros-padrão (ep)

Table 7 - Means of daily gain weight (kg/day) of purebred Santa Inês (SS) lambs and its crosses with Texel (TS), lle de France (FS) and Bergamácia (BS) and the respective standars errors (ep)

\begin{tabular}{|c|c|c|c|c|c|c|c|}
\hline \multirow[t]{2}{*}{$\begin{array}{l}\text { Grupo genético } \\
\text { Genetic group }\end{array}$} & \multirow[t]{2}{*}{$\begin{array}{l}\text { Sexo } \\
\text { Sex }\end{array}$} & \multicolumn{2}{|c|}{$\begin{array}{l}1 \underline{\mathrm{a}} \text { fase } \\
1^{\text {st }} \text { phase }\end{array}$} & \multicolumn{2}{|l|}{$\begin{array}{c}2 \underline{\mathrm{a}} \text { fase } \\
2^{\text {nd }} \text { phase }\end{array}$} & \multicolumn{2}{|c|}{$\begin{array}{l}3 \underline{\mathrm{a}} \text { fase } \\
3^{r d} \text { phase }\end{array}$} \\
\hline & & $15-25 \mathrm{~kg}$ & ep & $25-35 \mathrm{~kg}$ & ep & $35-45 \mathrm{~kg}$ & ep \\
\hline \multirow[t]{2}{*}{ SS } & $\mathrm{M}$ & $0,205^{\mathrm{BaA}}$ & 0,019 & $0,261^{\mathrm{AaA}}$ & 0,022 & $0,183^{\mathrm{BaBC}}$ & 0,022 \\
\hline & $\mathrm{F}$ & $0,172^{\text {Ааa }}$ & 0,019 & $0,143^{\mathrm{AB} \text { bab }}$ & 0,019 & $0,116^{\mathrm{Bb} \mathbf{b}}$ & 0,022 \\
\hline \multirow[t]{2}{*}{$\mathrm{TS}$} & M & $0,237^{\text {AaA }}$ & 0,022 & $0,277^{\mathrm{AaA}}$ & 0,022 & $0,261^{\mathrm{AaA}}$ & 0,019 \\
\hline & $\mathrm{F}$ & $0,206^{\text {Ааa }}$ & 0,019 & $0,192^{\mathrm{Aba}}$ & 0,019 & $0,191^{\mathrm{Aba}}$ & 0,022 \\
\hline \multirow[t]{2}{*}{ FS } & M & $0,244^{\mathrm{BaA}}$ & 0,022 & $0,307^{\mathrm{AaA}}$ & 0,022 & $0,244^{\mathrm{Ba} \mathbf{A B}}$ & 0,027 \\
\hline & $\mathrm{F}$ & $0,234^{\text {Ааa }}$ & 0,027 & $0,194^{\mathrm{Aba}}$ & 0,027 & $0,199^{\text {Ааа }}$ & 0,027 \\
\hline \multirow[t]{2}{*}{$\mathrm{BS}$} & M & $0,218^{\mathrm{AaA}}$ & 0,019 & $0,167^{\mathrm{AaB}}$ & 0,027 & $0,173^{\mathrm{AaC}}$ & 0,022 \\
\hline & $\mathrm{F}$ & $0,200^{\mathrm{Aa} a}$ & 0,019 & $0,127^{\mathrm{Bab}}$ & 0,017 & $0,127^{\mathrm{Bab}}$ & 0,017 \\
\hline
\end{tabular}

Médias seguidas de letras diferentes diferem entre si pelo teste $t(P<0,05)$. Nas linhas, letras maiúsculas para diferenciar as fases de crescimento; nas colunas: minúsculas para diferenciar o sexo em cada grupo genético, minúscula em negrito para diferenciar o grupo genético nas fêmeas e maiúscula em negrito para diferenciar o grupo genético nos machos. Means followed by different letters differ $(P<.05)$ by test $t$. In the lines, capital letters are used to differentiate the growth phases; in the columns: small letters are used to differentiate sex in each genetic group, small letters in boldface are used to differentiate the genetic group in the females and capital letters in boldface differentiate the genetic group in the males.

$\mathrm{M}=$ Macho $($ Male $)$ e $\mathrm{F}=$ Fêmea $($ Female) .

e terceira fases, os cordeiros do grupo Santa Inês puro apresentaram ganhos um pouco melhores que os BS, chegando a igualar-se aos cordeiros oriundos dos cruzamentos com as raças especializadas (Texel e Ile de France) para produção de carne. O ganho médio ( $212 \mathrm{~g} /$ dia) dos cordeiros machos SS, entre 15 e $25 \mathrm{~kg}$, neste trabalho, foi superior ao citado por Santos (1999), de $184 \mathrm{~g} / \mathrm{dia}$, para cordeiros machos SS, entre 15 e $25 \mathrm{~kg}$. Nas outras duas fases, houve diminuição do ganho do Santa Inês, enquanto Santos (1999) citou aumentos no ganho (215 e 216 g/dia, respectivamente, para a segunda e terceira fases), além de ganho médio de $158 \mathrm{~g} /$ dia para cordeiros Bergamácia, entre 15 e $25 \mathrm{~kg}$, valor inferior ao obtido para animais cruzas Bergamácia x Santa Inês (225 g/ dia), no presente trabalho. Esse resultado é indicativo do potencial da raça Santa Inês em cruzamentos com a Bergamácia, para a produção de carne. Entretanto, ao comparar as outras duas fases (25 a $35 \mathrm{~kg}$ e 35 a $45 \mathrm{~kg}$ ), no trabalho de Santos (1999), foram relatados valores superiores (254 e $252 \mathrm{~g} /$ dia, respectivamente) para cordeiros Bergamácia puros em relação aos cordeiros cruzas desta pesquisa (166 e $163 \mathrm{~g} / \mathrm{dia}$, respectivamente, para as duas fases). É claro que devem ser ponderadas as condições de condução de cada trabalho.

Os resultados referentes aos dias necessários para atingir o peso de abate, durante as fases de crescimento, são apresentados na Tabela 8. O tempo em que os cordeiros permaneceram em confinamento é suficiente para ganhar $10 \mathrm{~kg}$ de peso. Apenas os animais SS entre 25 e $35 \mathrm{~kg}$ e entre 35 e $45 \mathrm{~kg}$ de peso apresentaram diferenças $(\mathrm{P}<0,05)$ entre sexos, ao passo que as fêmeas SS necessitaram de mais tempo para atingir o peso de abate. Não houve diferenças entre os grupos genéticos no número de dias necessários para que os animais de $15 \mathrm{~kg}$ chegassem ao peso de abate de $25 \mathrm{~kg}$. Na segunda fase de crescimento, os machos e as fêmeas BS necessitaram de mais dias $(\mathrm{P}<0,05)$ para atingir $35 \mathrm{~kg}$ de peso vivo em relação aos grupos TS e FS. Para chegar aos 45 $\mathrm{kg}$ de peso vivo, os cordeiros machos TS necessitaram de menor tempo que os BS $(\mathrm{P}<0,05)$. As fêmeas TS e FS despenderam menor tempo que as cordeiras SS e BS $(\mathrm{P}<0,05)$. De maneira geral, os resultados encontrados para número de dias necessários para atingir o peso de abate foram muito variáveis, em decorrência da diferença na maturidade dos diferentes grupos genéticos. De acordo com Sainz (1996), o crescimento do animal é lento na primeira fase de vida, posteriormente acelera ao máximo e, então, começa a diminuir. No presente trabalho, não foi avaliado o crescimento logo após o nascimento, mas, em relação às fases avaliadas, para as fêmeas SS e $\mathrm{BS}$, o crescimento mais acelerado ocorreu na primeira fase, quando houve menor $(\mathrm{P}<0,05)$ número de dias que as outras fases. 
Tabela 8 - Médias de dias em confinamento de cordeiros Santa Inês puros (SS) e cruzas com Texel (TS), lle de France (FS) e Bergamácia (BS) e os respectivos erros-padrão (ep)

Table 8 - Means of days in feedlot of purebred Santa Inês (SS) lambs and its crosses with Texel (TS), Ile de France (FS) and Bergamacia (BS) and the respective standard errors (ep)

\begin{tabular}{|c|c|c|c|c|c|c|c|}
\hline \multirow[t]{2}{*}{$\begin{array}{l}\text { Grupo genético } \\
\text { Genetic group }\end{array}$} & \multirow[t]{2}{*}{$\begin{array}{c}\text { Sexo }^{2} \\
\text { Sex }^{2}\end{array}$} & \multicolumn{2}{|c|}{$\begin{array}{l}1 \underline{\mathrm{a}} \text { fase } \\
1^{\text {st }} \text { phase }\end{array}$} & \multicolumn{2}{|c|}{$\begin{array}{c}2 \underline{\mathrm{a}} \text { fase } \\
2^{\text {nd }} \text { phase }\end{array}$} & \multicolumn{2}{|c|}{$\begin{array}{l}3 \text { a fase } \\
3^{\text {rd }} \text { phase }\end{array}$} \\
\hline & & $15-25 \mathrm{~kg}$ & ep & $25-35 \mathrm{~kg}$ & ep & $35-45 \mathrm{~kg}$ & ep \\
\hline \multirow[t]{2}{*}{ SS } & $\mathrm{M}$ & $52^{\mathrm{BaA}}$ & 7,1 & $55^{\mathrm{ABbAB}}$ & 8,2 & $65^{\mathrm{AbAB}}$ & 8,2 \\
\hline & $\mathrm{F}$ & $66^{\text {Baa }}$ & 7,1 & $75^{\text {Ааab }}$ & 7,1 & $92^{\mathrm{Aaa}}$ & 8,2 \\
\hline \multirow[t]{2}{*}{$\mathrm{TS}$} & M & $46^{\mathrm{AaA}}$ & 8,2 & $37^{\mathrm{Aa} \mathbf{B}}$ & 8,2 & $43^{\mathrm{AaB}}$ & 7 \\
\hline & $\mathrm{F}$ & $55^{\mathrm{Aaa}}$ & 7 & $58^{\mathrm{Aab}}$ & 7 & $56^{\mathrm{Aab}}$ & 8 \\
\hline \multirow[t]{2}{*}{ FS } & $\mathrm{M}$ & $45^{\mathrm{AaA}}$ & 8 & $36^{\mathrm{Aa} \mathbf{B}}$ & 8 & $47^{\mathrm{AaAB}}$ & 10 \\
\hline & $\mathrm{F}$ & $49^{\mathrm{Aaa}}$ & 10 & $52^{\mathrm{Aab}}$ & 10 & $53^{\mathrm{Aab}}$ & 10 \\
\hline \multirow[t]{2}{*}{ BS } & $\mathrm{M}$ & $50^{\mathrm{AaA}}$ & 7 & $69^{\mathrm{AaA}}$ & 10 & $66^{\mathrm{AaA}}$ & 8 \\
\hline & $\mathrm{F}$ & $57^{\mathrm{Baa}}$ & 7 & $92^{\text {Ааa }}$ & 6 & $90^{\text {Ааa }}$ & 6 \\
\hline
\end{tabular}

Médias seguidas de letras diferentes diferem entre si pelo teste $t(P<0,05)$. Nas linhas, letras maiúsculas para diferenciar as fases de crescimento; nas colunas: minúsculas para diferenciar o sexo em cada grupo genético, minúscula em negrito para diferenciar o grupo genético nas fêmeas e maiúscula em negrito para diferenciar o grupo genético nos machos. Means followed by different letters differ $(P<.05)$ by $t$ test. In the lines, capital letters are used to differentiate the growth phases; in the columns: small letters are used to differentiate sex in each genetic group, small letters in boldface are used to differentiate the genetic group in the females and capital letters in boldface differentiate the genetic group in the males. $\mathrm{M}=$ Macho $($ Male $)$ e $\mathrm{F}=$ Fêmea $($ Female) .

Os valores da idade média de abate encontram-se na Tabela 9. Os cordeiros abatidos aos 15 e $25 \mathrm{~kg}$ de peso vivo não apresentaram diferenças $(\mathrm{P}>0,05)$ de idade entre os sexos, dentro de cada grupo genético, nem entre os grupos genéticos em cada sexo. Aos 35 e $45 \mathrm{~kg}$, as fêmeas SS foram abatidas com idade superior aos machos do mesmo grupo. Também aos $35 \mathrm{~kg}$, as fêmeas TS foram abatidas mais velhas $(\mathrm{P}<0,05)$ que os machos TS. Com $35 \mathrm{~kg}$, os cordeiros machos BS apresentaram idade de abate superior $(\mathrm{P}<0,05)$ aos machos dos demais grupos genéticos. Aos $45 \mathrm{~kg}$, os machos SS foram abatidos com idade maior $(\mathrm{P}<0,05)$ que os cordeiros TS e semelhantes aos grupos FS e BS. As fêmeas SS com $35 \mathrm{~kg}$ apresentaram idades médias superiores $(\mathrm{P}<0,05)$ às cordeiras TS e FS e semelhantes $(\mathrm{P}>0,05)$ às $\mathrm{BS}$. A idade média de abate, obtida pelos cordeiros SS, TS e FS, abatidos aos $35 \mathrm{~kg}$, foi de 149 dias, valor superior ao encontrado por Latif \& Owen (1980), média de 121 dias, para cordeiros Texel x FinnDorset, machos e fêmeas, abatidos com 36,3 e $31,3 \mathrm{~kg}$, respectivamente. Infere-se que as ovelhas Santa Inês usadas no presente trabalho proporcionaram ganho inferior aos seus cordeiros, em relação às ovelhas utilizadas por esses autores. Todos os coeficientes de regressão foram $(\mathrm{P}<0,05)$ maiores que zero, indicando que a idade se elevou de forma linear $(\mathrm{P}<0,05)$, com o aumento do peso de abate, observando-se os maiores coeficientes para as fêmeas. De acordo com o valor do coeficiente, o grupo genético TS apresentou taxas menores que os demais, para machos e fêmeas, comprovando que este grupo atingiu a maturidade mais precocemente.

Constam da Tabela 10 as médias de peso do corpo vazio (PCVZ). Aos $25 \mathrm{~kg}$, as fêmeas SS e TS apresentaram pesos maiores $(\mathrm{P}<0,05)$ que os machos dos mesmos grupos genéticos. Nos outros pesos, não ocorreram diferenças entre machos e fêmeas. Esse resultado é semelhante ao encontrado por Pires et al. (1999), que relataram semelhanças entre os pesos vazios de machos e de fêmeas. Aos 15 e $25 \mathrm{~kg}$, não houve diferenças entre os grupos genéticos, para machos e fêmeas, mostrando que, no início do crescimento, a genética não chegou a afetar o peso vazio. Entretanto, a partir de $35 \mathrm{~kg}$, algumas diferenças ocorreram, em função da diferença na maturidade de cada grupo. Com 35 e $45 \mathrm{~kg}$, os machos TS e FS mostraram pesos vazios menores $(\mathrm{P}<0,05)$ e as fêmeas dos mesmos grupos também apresentaram pesos menores $(\mathrm{P}<0,05)$, mas somente aos $45 \mathrm{~kg}$. Este resultado deve-se, provavelmente, ao fato de cordeiros cruzas com raças especializadas (Texel e Ile de France), em pesos mais elevados, apresentarem maiores quantidades de conteúdo do aparelho digestivo, no momento do abate (média de $6,47 \mathrm{~kg}$ para cordeiros TS e FS e $5,85 \mathrm{~kg}$ para cordeiros SS e BS). Os coeficientes de determinação das equações de regressão mostram 


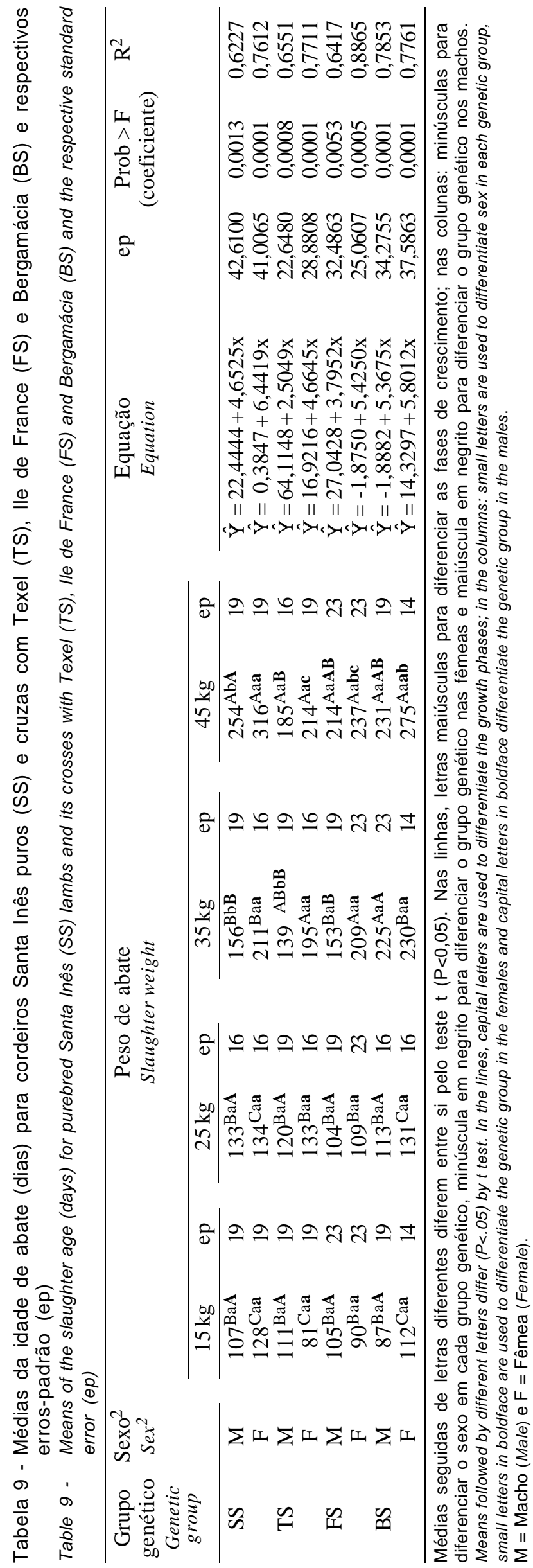

que, para PCVZ, exite adequado ajuste dos dados, com pouca dispersão, como esperado. Resultados semelhantes foram encontrados por Santos (1999), trabalhando com cordeiros Santa Inês e Bergamácia, abatidos aos $15,25,35$ e $45 \mathrm{~kg}$ de peso vivo. Os coeficientes de regressão "b" foram significativos $(\mathrm{P}<0,05)$ para machos e fêmeas de todos os grupos genéticos, indicando aumento linear do PCVZ, com o aumento do peso de abate. O coeficiente médio (b) para PVCZ $(0,8568)$ foi semelhante ao encontrados por Santos (1999), de 0,8936, para cordeiros Santa Inês.

Os valores médios constatados para rendimento comercial da carcaça (RCC) são mostrados na Tabela 11.

Aos $25 \mathrm{~kg}$ de peso vivo, as cordeiras SS e BS apresentaram RCC maior $(\mathrm{P}<0,05)$ que os machos dos mesmos grupos. Todas as cordeiras abatidas aos $35 \mathrm{~kg}$, com exceção das fêmeas TS, tiveram maior $(\mathrm{P}<0,05)$ RCC que os machos, ocorrendo o mesmo aos $45 \mathrm{~kg}$, com exceção das cordeiras SS, que apresentaram RCC semelhante ao dos machos. O maior rendimento de carcaça das fêmeas era esperado, principalmente em estádios de desenvolvimento mais avançados, por apresentarem maior deposição de gordura. A semelhança observada no grupo FS corrobora o resultado de Pires et al. (1999), que citaram rendimentos semelhantes entre machos e fêmeas.

Entre os grupos genéticos, dentro de cada peso de abate, aos $25 \mathrm{~kg}$ as cordeiras TS apresentaram menor $(\mathrm{P}<0,05) \mathrm{RCC}$ que as SS, ao passo que, aos $35 \mathrm{~kg}$, os machos FS obtiveram menor $(\mathrm{P}<0,05)$ RCC que os cordeiros TS. Aos 15 e $45 \mathrm{~kg}$ de peso vivo, não foram observadas diferenças entre os grupos genéticos. Segundo Galvão et al. (1991), o rendimento diferente entre raças pode estar "confundido", pois, quando se abatem animais de distintos grupos genéticos, em pesos iguais, a desigualdade pode ser atribuída ao grau de maturidade entre genótipos. O contrário também pode acontecer em animais abatidos em pesos diferentes, quando o rendimento é afetado pelo peso corporal.

O rendimento comercial médio $(47,16 \%)$ para animais abatidos aos $25 \mathrm{~kg}$ foi superior ao encontrado por Pires et al. (2000), de 45,87\%. Os coeficientes de regressão linear, para todos os grupos, foram positivos $(\mathrm{P}<0,05)$, comprovando o aumento linear do rendimento de carcaça, com o avanço do peso de abate. De acordo com Preston \& Willis, (1974), Oliveira et al. (1998) e

\section{R. Bras. Zootec., v.33, n.6, p.1591-1603, 2004}




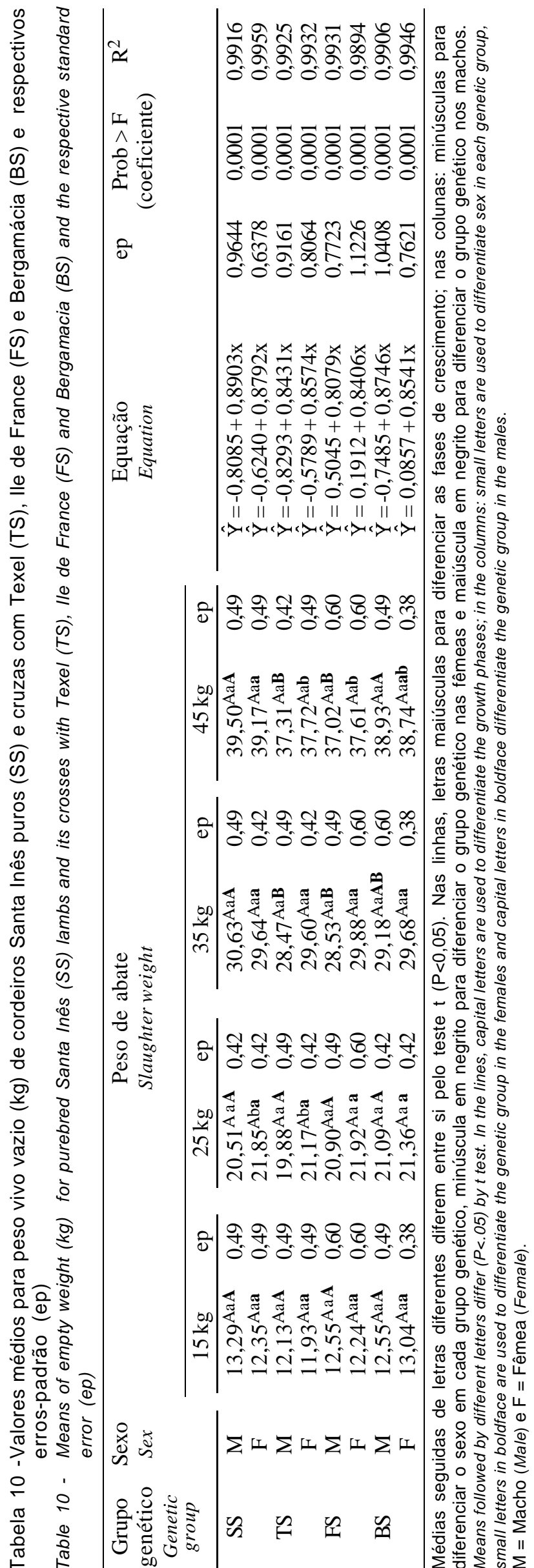

Pires et al. (2000), o aumento do peso de abate pode elevar o rendimento das carcaças. Porém, altos rendimentos podem estar associados ao excessivo grau de gordura (Carson et al., 1999; Siqueira, 2000) ou à baixa porcentagem de componentes nãoconstituintes da carcaça.

Os coeficientes obtidos pelas fêmeas foram maiores, indicando aumento do rendimento em maiores ritmos, o que é explicado pela deposição maior de gordura na carcaça, em decorrência da ação de hormônios e da precocidade.

\section{Conclusões}

O uso de raça especializada para carne, no cruzamento com Santa Inês, como a Texel e a Ile de France, melhorou o desempenho dos animais.

Os cordeiros Texel x Santa Inês, apresentaram os melhores resultados e, conseqüentemente, foram abatidos em idades menores, em função dos maiores ganhos e das melhores tax as de conversão alimentar; o contrário foi observado para os cordeiros Bergamácia x Santa Inês.

\section{Literatura Citada}

AGRICUlTURAL RESEARCH COUNCIL - ARC. The nutrient requeriment of farm animals. London: 1980 $351 \mathrm{p}$.

AZZARINI, M.; PONZONI, R. Aspectos modernos de la produción ovina. Montevideo: Universidade de la Republica. Departamento de Publicaciones, 1971. 75p.

CARSON, A.F.; MOSS, B.W.; STEEN, R.W. et al. Effects of the percentage of Texel or Rouge de I'Ouest genes in lambs on carcass characteristics and meat quality. Animal Science, v.69, n.1, p.81-92, 1999.

CARVALHO, S.; PIRES, C. C.; PERES, J. R. R. et al. Desempenho de cordeiros machos inteiros, machos castrados e fêmeas, alimentados em confinamento. Ciência Rural, v.29, n.1, p.129-133, 1999.

CROUSE, J.D.; BUSBOOM, J.R.; FIELD, R.A. et al. The effects of breed, diet, Sex, location and slaughter weight on lamb growth, carcass composition and meat flavor. Journal of Animal Science, v.53, n.2, p.376-386, 1992.

FAO. Animal production. Roma, 2000. n.49. (FAO Statistics Series, 130).

FIGUEIRÓ, P.R.P. Manejo nutricional para produção de ovinos tipo lã e tipo carne. In: SIMPÓSIO PARANAENSE DE OVInOCUltura, 3., 1986, Guarapuava. Anais... Guarapuava: 1986. p.37-45.

FIGUEIRÓ, P.R.P. Efeito do cruzamento da raça Hampshire Down e Romney Marsh na produção de cordeiros para abate. Revista do Centro de Ciências Rurais, v.9, n.4, p.421-428, 1979 .

\section{R. Bras. Zootec., v.33, n.6, p.1591-1603, 2004}



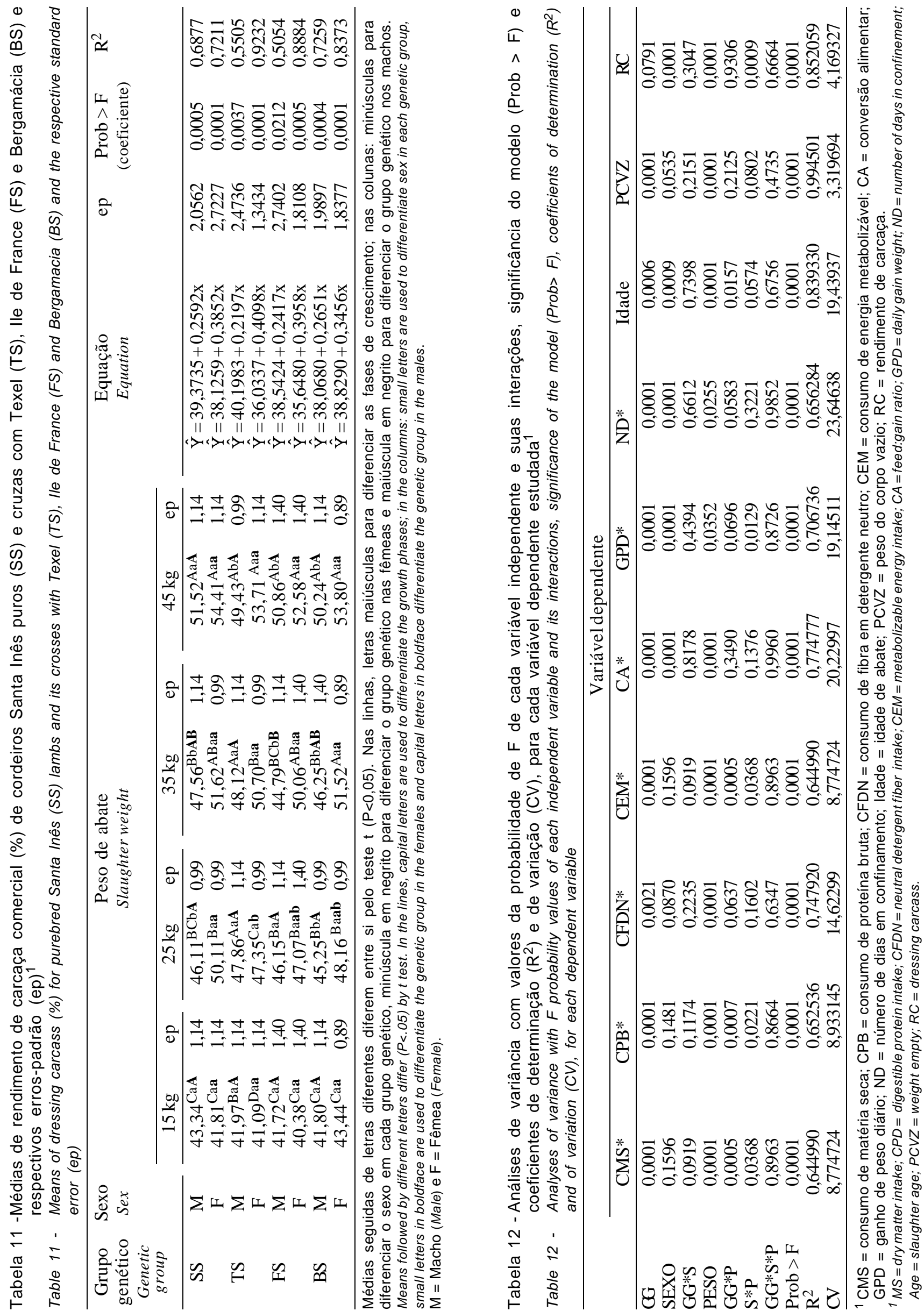

\section{R. Bras. Zootec., v.33, n.6, p.1591-1603, 2004}


FURUSHO, I.F. Efeito da utilização da casca de café, in natura e tratada com uréia, sobre o desempenho e características de carcaça de cordeiros terminados em confinamento. Lavras: Universidade Federal de Lavras, 1995. 72p. Dissertação (Mestrado em Zootecnia) Universidade Federal de Lavras, 1995.

GALVÃO, J.G.C.; FONTES, C.A.A.; PIRES, C.C. et al. Características e composição física de carcaça de bovinos não-castrados, abatidos em três estágios de maturidade de três grupos raciais. Revista da Sociedade Brasileira de Zootecnia, v.20, n.5, p.502-512, 1991.

KEMP, J.D.; MAHYUDDIN, M.; ELY, D.G. et al. Effect of feeding systems, slaughter weight and sex on organoleptic properties, and fatty acid composition of lamb. Journal of Animal Science, v.51, n.2, 1981.

KEMPSTER, A.J.; CROSTON, D.; GUY, D.R. et al. Growth and carcass characteristics of crossbred lambs by tem sire breeds, compared at the same estimated carcass subcutaneus fat proportion. Animal Production, v.44, p.83-98, 1987.

KIRKPATRICK, D.E.; STEEN, W.J. Performance, carcass composition and energy retention of lambs offered two contrasting grass-based forages. Journal of Agricultural Science, v.132, p.117-126, 1999.

LAFIT, M.G.A.; OWEN, E. A note on the growth performance and carcass composition of Texel and Suffolk sired lambs in a intensive system. Animal Production, v.30, n.2, p.311-314, 1980 .

OLIVEIRA, N. M.; OSÓRIO, J.C. S.; SELAIVE-VILLARROEL, A. et al. Produção de carne em ovinos de cinco genótipos. 5. Estimativas de qualidade e peso de carcaça através do peso vivo. Ciência Rural, v.28, n.4, p.537-724, 1998.

OSÓRIO, M.T.M.; SIERRA, I.; SAÑUDO, C. et al. Influência da raça, sexo e peso/idade sobre o rendimento da carcaça em cordeiros. Ciência Rural, v.29, n.1, p.139-142, 1999.

PÉREZ, J.R.O. Alguns aspectos relacionados com a qualidade da carcaça e da carne ovina. In: SIMPÓSIO PAULISTA DE OVINOCULTURA, 4., 1995, Campinas. Anais ... Campinas: ASPACO - CATI - FMVZ/UNESP - SENAR, 1995. p. 125-139.

PIRES, C.C.; ARAÚJO, J.R.; BERNARDES, R.A.C. et al. Desempenho e características da carcaça de cordeiros de três grupos genéticos abatidos ao mesmo estágio de maturidade. Ciência Rural, v.29, n.1, p.155-158, 1999.
PIRES, C.C.; SILVA, L.F.; SCHLICK, F.E. et al. Cria e terminação de cordeiros confinados. Revista do Centro de Ciências Rurais, v.30, n.5, p.875-880, 2000.

PRESTON, T.R.; WILLIS, M.B. Intensive beef production. 2.ed. Oxford: Pergamon Press, 1974. 546p.

PREZIUSO, G.; RUSSO, C.; CASAROSA, L. et al. Effect of diet energy source on weight gain and carcass characteristics of lambs. Small Ruminant Research, v.33, p.9-15, 1999.

SAINZ, R.D. Qualidade das carcaças e da carne ovina e caprina. In: REUNIÃO ANUAL DA SOCIEDADE BRASILEIRA DE ZOOTECNIA, 33., SIMPÓSIO INTERNACIONAL SOBRE TÓPICOS ESPECIAIS EM ZOOTECNIA, 1996, Fortaleza. Anais... Fortaleza: Sociedade Brasileira de Zootecnia, 1996. p.3-14.

SANTOS, C.L. Estudo do desempenho, das características da carcaça e do crescimento alométrico de cordeiros das raças Santa Inês e Bergamácia. Lavras: Universidade Federal de Lavras, 142p. Dissertação (Mestrado em Zootecnia) - Universidade Federal de Lavras, 1999.

STATISTICAL ANALYSES SYSTEM - SAS. User's guide: statistics. 5.ed. Cary: 1985. 956p.

SILVA, D.J. Análise de alimentos (métodos químicos e biológicos). Viçosa, MG: Universidade Federal de Viçosa, 1981. 166p.

SIQUEIRA, E.R. Produção de carne de cordeiros. In: ENCONTRO MINEIRO DE OVINOCULTURA, 1., 2000, Lavras. Anais... Lavras: Universidade Federal de Lavras, 2000. p.129-149.

SIQUEIRA, E.R.; OSÓRIO, J.C.S.; GUERREIRO, J.L.V. et al. Desempenho de cordeiros machos e fêmeas da raça Ideal e cruzas Texel x Ideal, criados em pastagem nativa. Pesquisa Agropecuária Brasileira, v.19, p.1523-1528, 1984.

TEIXEIRA, J.C. Fisiologia digestiva dos animais ruminantes. Lavras, MG: Universidade Federal de Lavras, 1991. 185p.

WOLF, B.T.; SMITH, S.; SALES, D.I. Growth and carcass composition in the crossbred progeny of six terminal sire breeds of sheep. Animal Production, v.31, p.307-313, 1980.

Recebido em: 12/12/02 Aceito em: 18/03/04 